\title{
Research Paper: Cardiovascular Conditions in Patients With Aluminum Phosphide Poisoning
}

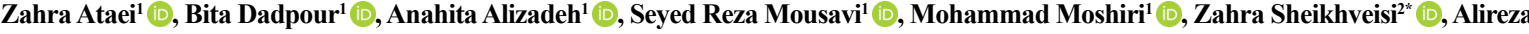 \\ Banaye Yazdipour ${ }^{3,4}$ (i)
}

1. Medical Toxicology Research Center, Mashhad University of Medical Sciences, Mashhad, Iran.

2. Department of Medical Toxicology, Emam Reza Hospital, Mashhad University of Medical Sciences, Mashhad, Iran.

3. Department of Health Information Management, School of Allied Medical Sciences, Tehran University of Medical Sciences, Tehran, Iran.

4. Students' Scientific Research Center (SSRC), Tehran University of Medical Sciences (TUMS), Tehran, Iran.

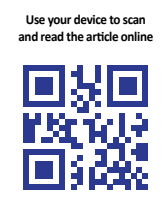

Cittat On: Ataei Z, Dadpour B, Alizadeh A, Mousavi SR, Moshiri M, Sheikhveisi Z, et al. Cardiovascular Conditions in Patients With Aluminum Phosphide Poisoning. International Journal of Medical Toxicology and Forensic Medicine. 2021; 11(2):30188. https://doi.org/10.32598/ijmtfm.v11i2.30188

doi https://doi.org/10.32598/ijmtfm.v11i2.30188

(c) (i) (3)

Article info:

Received: 27 Apr 2020

First Revision: 07 Jul 2020

Accepted: 02 Nov 2020

Published: 15 Jun 2021

\section{Keywords:}

Aluminum phosphide, Blood poisoning, Echocardiography, Bicarbonates

\section{ABSTRACT}

Background: Aluminum Phosphide (AIP) is a well-known rodenticide and insecticide, used as a fumigant to control pests and rodents in grain-storage facilities. Its intoxication presents a medical emergency that requires early rigorous management. This study aimed to investigate cardiac function by Electrocardiogram (ECG) changes in patients with AlP intoxication. We also explored the potential relationship between low bicarbonate and cardiac function

Methods: This cross-sectional study investigated 42 patients in the age range of 17-47 years, with a history of orally-administered AIP poisoning, known as "rice tablet", admitted to the toxicology ward of Imam Reza Hospital from March 2019 to March 2021. The study patients' demographic data were collected by trained interviewers, using pretested questionnaires. Systolic and diastolic blood pressure, as well as blood samples, were measured 12 hours from admission. Echocardiography was performed during the first 12 hours and on the fifth-day post-admission. All statistical analysis was performed using R 3.6.1. The significance level was set at 0.05 for all statistical tests.

Results: In total, $48.78 \%$ of patients presented normal bicarbonate levels, and $24.39 \%$ and $26.83 \%$ had moderate and severe acidity, respectively. Moderately and severely decreased Left Ventricular Ejection Fraction (LVEF) was observed among 21 (51.2\%) and 10 (24.4\%) patients, respectively. Furthermore, mild Right Ventricular (RV) function was observed among $11(26.8 \%)$ patients. A statistically significant association was observed between bicarbonate level and RV function $(\mathrm{P}<0.001)$ and $\operatorname{LVEF}(\mathrm{P}<0.001)$. Besides, $19.5 \%$ of the explored patients expired. The proportion of expired patients was significantly higher in patients with mild RV function, compared to the other patients $(\mathrm{P}<0.001)$.

Conclusion: Acute AlP intoxication is a worldwide serious problem. Severe metabolic acidosis and ECG abnormalities are associated with poor outcomes in this respect. Thus, conducting early ECG and echocardiography could be desirable instruments to predict prognosis. There is no antidote for AlP poisoning; thus, the replacement of a safer agent for in-store grain protection is strongly suggested. 


\section{Introduction}

A

luminum Phosphide (AIP) is a wellknown rodenticide and insecticide, used as a fumigant to control pests and rodents in grain-storage facilities [1]. AlP is an easily accessible and low-cost toxin and a major cause of poisoning in developing countries [2]. It is available in different forms, such as tablets, pellets, and compressed disks, containing 56\% AlP and $44 \%$ ammonium carbonate. The combination of the moisture in the air and phosphide grains sets off phosphine, i.e. an active form of the pesticide. Following ingestion, AIP also reacts with hydrochloric acid and water in the stomach which leads to the immediate release of the Phosphine gas $\left(\mathrm{PH}_{3}\right)$ [3]. Phosphine is a mitochondrial poison that interferes in protein synthesis and enzymes; it may lead to multi-organ dysfunction, particularly affecting cardiovascular and respiratory systems [4]. Evidence suggested that AlP intoxication causes severe metabolic acidosis, the rapid onset of shock, and cardiac arrhythmias. The heart rate often decreases per the degree of shock [5]; thus, Electrocardiography (ECG) may indicate sinus tachycardia or tachyarrhythmia. ST-elevation, ST-depression, T-wave changes, and the widening of the QRS complex can also appear in AlP poisoning [6-8]. Furthermore, if a patient survives from cardiac arrhythmias and sinus arrest, ECG changes may last for three weeks to normalize [5, 8]. Accordingly, the variation in ECG can help identify the stage of the poisoning.

Overall, AlP intoxication is a medical emergency that requires early rigorous management. It consists of a spectrum of clinical and laboratory findings that should be applied for therapeutic procedures. Despite the importance of the subject, comprehensive reviews evaluating cardiac function in patients with AIP poisoning in the middle-east countries are scarce. Therefore, the current study aimed to investigate cardiac function by ECG changes in patients with AlP intoxication. We also explored the potential relationship between low bicarbonate and cardiac function in this population.

\section{Materials and Methods}

This cross-sectional study was conducted in Mashhad City, Iran. The study participants were Iranian urban residents who were admitted to the toxicology ward of Imam Reza Hospital from March 2019 to March 2021 with orally-administered AlP poisoning, known as "rice tablet". Initially, all study participants provided written informed consent. Subjects with a history of Ischemic Heart Disease (IHD), Hypertension (HTN), valvular heart disease, or congenital heart disease, a history of taking anti-cancer drugs, like cytostatic or chest X-ray were excluded from this study. Due to the strong association between age and Cardiovascular Diseases (CVDs), subjects aged $\geq 45$ years (whether having a history of CVDs or not) were also excluded from our study. Additionally, patients whose results confirmed the concurrent oral ingestion of AlP and other drugs or toxins were also excluded from this research.

on the study participants' demographic data, including age and gender were collected by trained interviewers, using pretested questionnaires. Systolic Blood Pressure (SBP) and Diastolic Blood Pressure (DBP) were measured in a sitting position on the right arm 12 hours after admission. Blood samples were collected and blood $\mathrm{PH}$ was measured 12 hours from admission. Moreover, echocardiography was performed during the first 12 hours and on the fifth-day post-admission.

According to Gupta et al. [9], trans-thoracic echocardiography was performed on the first and fifth days postadmission for subjects who survived. Left Ventricular (LV) dimensions and Left Ventricular Ejection Fraction (LVEF) were examined in the parasternal long-axis view. Permission to undertake the study was obtained from the Ethics Committee of Mashhad University of Medical Sciences, (No.: MUMS.MEDICAL. REC.1398.828), Mashhad, Iran.

The obtained data are represented as mean and standard deviation [10] as well as frequency and percentage. Chi-squared test and Kendal's tau-b coefficient of association were calculated. All statistical analyses were conducted using R 3.6.1 at the significance level of 0.05 .

\section{Results}

In this study, 41 patients poised with AlP were included. In total, $56.1 \%$ of the study subjects were male and $43.9 \%$ were female. The Mean \pm SD age of the study patients was 27.56 \pm 7.09 years (age range: 17-47 years). The Mean \pm SD bicarbonate level of the study subjects was $18.23 \pm 5.19$. Twenty patients presented normal bicarbonate levels, 10 patients had moderate acidity, and 11 patients had severe acidity. The baseline characteristics of the study patients are listed in Table 1 .

LVEF was normal among 10 (24.4\%) patients, moderately and severely decreased LVEF were observed among $21(51.2 \%)$ and $10(24.4 \%)$ patients, respectively. Mild Right Ventricular (RV) function was observed among $11(26.8 \%)$ patients; also $12(29.3 \%)$ and 
Table 1. Baseline characteristics of admitted patients

\begin{tabular}{|c|c|c|}
\hline & & No. (\%) \\
\hline \multirow{2}{*}{ Gender } & Male & $23(56.1)$ \\
\hline & Female & $18(43.9)$ \\
\hline \multirow{3}{*}{ Bicarbonate level } & Normal & $20(48.8)$ \\
\hline & Moderate acidity & $10(24.4)$ \\
\hline & Sever acidity & $11(26.8)$ \\
\hline Age (Mean $\pm S D$ ) & & \\
\hline
\end{tabular}

$18(43.9 \%)$ patients presented moderate and good RV function, respectively. Most of the patients with normal bicarbonate levels presented good RV function (90\%); however, $40 \%$ of patients with moderate acidity and $63.6 \%$ of those with severe acidity indicated mild RV function. A significant association was observed between RV function and bicarbonate level (Kendal's tau-b coefficient $=-0.792 ; \mathrm{P}<0.001)$. Severely decreased LVEF was observed among $63.6 \%$ of patients with severe acidity and $30 \%$ of those with moderate acidity bicarbonate level; the same was not observed among the patients with normal LVEF. LVEF significantly increased with bicarbonate level (Kendal's tau-b coefficient $=-0.661$; $\mathrm{P}<0.001$ ) (Table 2).

In total, 8 (19.5\%) study participants expired. Among the group with mild RV function, 7 (63.6\%) patients died; $1(8.3 \%)$ patient with moderate RV function also died (Figure 1). The proportion of expired patients was significantly higher among the mild RV function group, compared to the other patients $(\mathrm{P}<0.001)$. Furthermore, a significantly higher proportion of patients with severely decreased LVEF (70\%) died, compared to those with moderately decreased LVEF (12.5\%) and normal LVEF $(0 \%)(\mathrm{P}<0.001)$ (Figure 2).

\section{Discussion}

The present study results provided clear support for the association between AlP intoxication and cardiac function. Accordingly, as the severity of AlLP poisoning increases, RV and LV function decreased, leading to a higher mortality rate. In this regard, echocardiography might be a good tool to predict the therapeutic outcomes.

Previous studies investigated the relationship between ECG abnormalities and severe AlP poisoning. In this regard, Kalawat et al. [11] conducted an observational study in 2016 and examined cardiovascular function and its clinical features in 50 patients with AlP poisoning who were admitted to the poisoning intensive care unit. They concluded that ECG was abnormal in 30 subjects out of 50. The most common abnormal ECG finding was sinus tachycardia (24\%), while the heart block was only detected in 2 out of 50 patients (4\%). Negative EEG findings included hypokinesia and decreased cardiac output.

Table 2. Association between bicarbonate level and RV function and LVEF

\begin{tabular}{|c|c|c|c|c|c|c|}
\hline \multirow{2}{*}{\multicolumn{2}{|c|}{ Bicarbonate Level }} & \multicolumn{3}{|c|}{ No. (\%) } & \multirow{2}{*}{$\mathbf{P}$} & \multirow{2}{*}{$\begin{array}{c}\text { Kendal's } \\
\text { Tau-b }\end{array}$} \\
\hline & & Normal & Moderate Acidity & Sever Acidity & & \\
\hline \multirow{3}{*}{$\begin{array}{c}\mathrm{RV} \\
\text { function* }\end{array}$} & Good & $18(90)$ & $0(0)$ & $0(0)$ & \multirow{3}{*}{$<0.001$} & \multirow{3}{*}{0.792} \\
\hline & Moderate & $2(10)$ & $6(60)$ & $4(36.4)$ & & \\
\hline & Mild & $0(0)$ & $4(40)$ & $7(63.6)$ & & \\
\hline \multirow{3}{*}{ LVEF** } & Normal & $10(50)$ & $0(0)$ & $0(0)$ & \multirow{3}{*}{$<0.001$} & \multirow{3}{*}{0.661} \\
\hline & Moderately decreased & $10(50)$ & $7(70)$ & $4(36.4)$ & & \\
\hline & Severely decreased & $0(0)$ & $3(30)$ & $7(63.6)$ & & \\
\hline
\end{tabular}




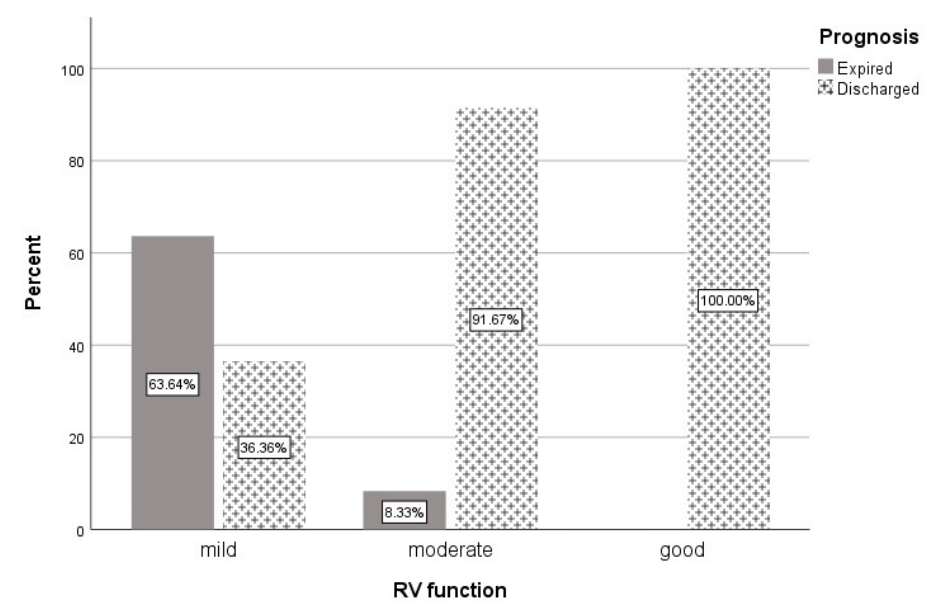

Figure 1. The prognosis of aluminum phosphide poisoned patients according to RV function

International Journal of
Medical Toxicology \& forensic Medicine

They argued that besides ECG, echocardiography is a useful tool to evaluate cardiac function in patients with AlP poisoning.

Agrawal et al. [12] also examined 7 cases of AlP poisoning with severe hemodynamic impairment. Two-dimensional echocardiography demonstrated a reduction in LV ejection fraction $(27.85 \%)$ in all patients. Moreover, 4 patients with a primary normal ECG survived; however, cardiac arrhythmias (VF \& AF) were noted in all 3 patients with mortality.

AlP is regionally known as "rice tablet". Iranians usually store large amounts of rice at home; to protect the rice from pests and rodents, they commonly use rice tablets. Therefore, it is highly accessible in Iran. AlP poisoning may cause multi-organ dysfunction. The majority of re- lated deaths occur because of cardiovascular dysfunction within the first 12-24 hours [13]. ECG findings include changes in ST-T (depression/elevation), reverse T-wave, and the broadening of the QRS complex [5, 7, 8, 14]. Arrhythmias and conduction disturbances consist of sinus tachycardia, myocardial infarction, atrial fibrillation, complete heart block, A-V Right Bundle Branch Block (RBBB) dissociation, and Left Bundle Branch Block (LBBB) [7, 14]. Nevertheless, ECG changes should return to normal up to three weeks, indicating a reversible myocardial injury [15]. However, studies reported that vasoactive drugs, i.e. commonly used to stabling blood pressure, may cause cardiac dysrhythmias in patients $[16,17]$.

Other evidence indicated that myocardial injury included elevated serum levels of cardiac enzymes (i.e.

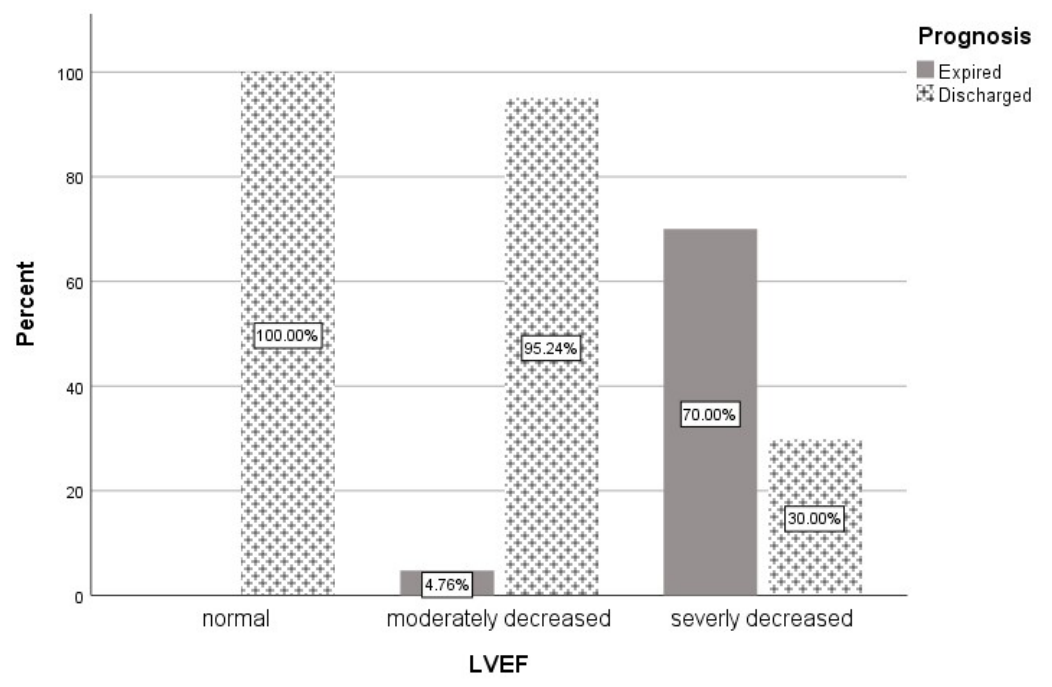

Figure 2. The prognosis of aluminum phosphide poisoned patients according to LVEF

International Journal of Medical Toxicology \& Forensic Medicine 
CPK-MB \& LDH) [18]. During the first 1 to 4 days, in up to $50 \%$ of subjects, decreased ejection fraction was observed on echocardiography due to hypokinesia of LV and intraventricular septum $[18,19]$.

The congestion of the heart and the separation and segmentation of myocardial fibers, non-specific myocytes vacuolation, neutrophil and eosinophil infiltration, and focal necrosis are repeated findings, i.e. detected in autopsy [20]. The exact mechanism underlying phosphine toxicity remains unexplained; however, we believe that the cause of cardiac dysfunction might be PH3-induced myocardial damage. In line with this theory, the present study revealed that in patients with severe acidity (low bicarbonate), RV and LV function decrease. Focal myocardial damage could lead to improper conduction pathways and arrhythmias; concurrent extensive myocardial damage could cause contractile dysfunction and hypotension [21].

Most of the patients who eventually died presented severely decreased LV and RV function. This condition was related to severe acidity in our study. In previous studies, cardiovascular shock, ECG abnormalities, and different types of cardiac arrhythmia were reported as predictors of poor prognosis [10, 22, 23]. There exists no specific antidote or comprehensive management for AlP poisoning. However, early diagnosis and constant intensive supportive care are critical in AlP poisoning management.

\section{Conclusion}

Acute AlP intoxication is a worldwide serious problem. Severe metabolic acidosis and ECG abnormalities are associated with poor treatment outcomes. Thus, early ECG and echocardiography could be good instruments to predict prognosis in these patients. There exists no antidote for AlP poisoning; thus, the replacement of a safer agent for in-store grain protection is strongly suggested.

\section{Ethical Considerations}

\section{Compliance with ethical guidelines}

This study was approved by the Ethics Committee of Mashhad University of Medical Sciences, Mashhad (No.: MUMS. MEDICAL. REC.1398.828).

\section{Funding}

This research did not receive any grant from funding agencies in the public, commercial, or non-profit sectors.

\section{Author's contributions}

Conceptualization and supervision: Zahra Sheikhveisi, Bita Dadpour; Writing - original draft, data analysis: Zahra Sheikhveisi, Alireza Banaye Yazdipour; Participation in its sequence alignment: Seyed Reza Mousavi, Zahra Ataei, Mohammad Moshiri; Final approval: All authors.

\section{Conflict of interest}

The authors declare that there is no conflict of interests.

\section{Acknowledgements}

The authors would like to appreciate the staff at Emam Reza Hospital.

\section{References}

[1] Hajouji Idrissi M, Oualili L, Abidi K, Abouqal R, Kerkeb $\mathrm{O}$, Zeggwagh AA. [Severity factors of aluminium phosphide poisoning (Phostoxin) (French)]. Ann Fr Anesth Reanim. 2006; 25(4):382-5. [DOI: 10.1016/j.annfar.2005.12.004] [PMID]

[2] Louriz M, Dendane T, Abidi K, Madani N, Abouqal R, Zeggwagh A. Prognostic factors of acute aluminum phosphide poisoning. Indian J Med Sci. 2009; 63(6):227-34 [DOI:10.4103/0019-5359.53386] [PMID]

[3] Mehrpour O, Alfred S, Shadnia S, Keyler DE, Soltaninejad $\mathrm{K}$, Chalaki N, et al. Hyperglycemia in acute aluminum phosphide poisoning as a potential prognostic factor. Hum Exp Toxicol. 2008; 27(7):591-5. [DOI:10.1177/0960327108096382] [PMID]

[4] Gupta S, Ahlawat SK. Aluminum phosphide poisoning-a review. J Toxicol Clin Toxicol. 1995; 33(1):19-24. [DOI:10.3109/15563659509020211] [PMID]

[5] Gurjar M, Baronia AK, Azim A, Sharma K. Aluminum phosphide poisoning: Clinical toxicity and outcome in eleven intensively monitored patients. Natl Med J India. 1988; 1(6):270-4. [DOI:10.4103/0974-2700.83868] [PMCID] [PMID]

[6] Raman R, Dubey M. The electrocardiographic changes in quick phos poisoning. Indian Heart J. 1985; 37(3):193-5. [PMID]

[7] Katira R, Elhence GP, Mehrotra ML, Srivastava SS, Mitra A, Agarwala R, et al. A study of Aluminum Phosphide (AlP) poisoning with special reference to electrocardiographic changes. J Assoc Physicians India. 1990; 38(7):471-3. [PMID]

[8] Siwach S, Yadav D, Arora B, Dalal S. Acute aluminum phosphide poisoning - an epidemiological, clinical and histopathological study. J Assoc Pysicians India. 1988; 36(10):594-6. [PMID]

[9] Gupta MS, Malik A, Sharma VK. Cardiovascular manifestations in aluminium phosphide poisoning with special refer- 
ence to echocardiographic changes. J Assoc Pysicians India. 1995; 43(11):773-4. [PMID]

[10] Lall SB, Sinha K, Mittra S, Seth S. An experimental study on cardiotoxicity of aluminium phosphide. Indian J Exp Biol. 1997; 35(10):1060-4. [PMID]

[11] Kalawat S, Thakur V, Thakur A, Punjabi ND. Cardiovascular profile of aluminium phosphide poisoning and its clinical significance. Int Adv Med. 2016; 3(4):859-64. [DOI:10.18203/2349-3933.ijam20163505]

[12] Agrawal VK, Bansal A, Singh RK, Kumawat BL, Mahajan P. Aluminum phosphide poisoning: Possible role of supportive measures in the absence of specific antidote. Indian J Crit Care Med. 2015; 19(2):109-12. [DOI:10.4103/09725229.151019] [PMID] [PMCID]

[13] Burgess JL, Morrissey B, Keifer MC, Robertson WO. Fumigant-related illnesses: Washington State's five-year experience. J Toxicol Clin Toxicol. 2000; 38(1):7-14. [DOI:10.1081/ CLT-100100909] [PMID]

[14] Khosla S, Nand N, Kumar P. Cardiovascular complications of aluminum phosphide poisoning. Angiology. 1988; 39(4):355-9. [DOI:10.1177/000331978803900404] [PMID]

[15] Sheta AA, El-Banna AS, Elmeguid RA, Mohamed HE, Gad $\mathrm{NH}$. A study of the predictive factors of mortality in acute poisoning with aluminum phosphide with special reference to echocardiography and SOFA score. Environ Sci Pollut Res Int. 2019; 26(32):33135-45. [DOI:10.1007/s11356-019-06457-4] [PMID]

[16] Marashi SM. A new concept against the priority of vasoactive agents in the management of severe hypotension associated with aluminum phosphide poisoning. Euro Rev Med Pharmacol Sci. 2016; 20(17):3517-8. https:/ / www.europeanreview.org/article/11355

[17] Farahani MV, Soroosh D, Marashi SM. Thoughts on the current management of acute aluminum phosphide toxicity and proposals for therapy: An evidence-based review. Indian J Crit Care Med. 2016; 20(12):724-30. [DOI:10.4103/09725229.195712] [PMID] [PMCID]

[18] Mehrpour O, Jafarzadeh M, Abdollahi M. Aluminium phosphide poisoning. Clinical toxicity and outcome in eleven intensively monitored patients. Arh Hig Rada Toksikol. 2012; 63(1):61-73. [DOI:10.2478/10004-1254-63-2012-2182]

[19] Bhasin P, Mital HS, Mitra A. An echocardiographic study in aluminium phosphide poisoning. J Assoc Physicians India. 1991; 39:851. https://scholar.google.com/scholar?hl=fa\&as_ $\mathrm{sdt}=0 \% 2 \mathrm{C} 5 \& \mathrm{q}=\mathrm{An}+$ echocardiographic + study $+\mathrm{in}+$ aluminiu $\mathrm{m}+$ phosphide+ poisoning\&btnG $=$

[20] Arora B, Punia RS, Kalra R, Chugh SN, Arora DR. Histopathological changes in aluminium phosphide poisoning. J Indian Med Assoc. 1995; 93(10):380-1. [PMID]

[21] Anand R, Binukumar BK, Gill KD. Aluminum phosphide poisoning: An unsolved riddle. J Appl Tocicol. 2011; 31(6):499-505. [DOI:10.1002/jat.1692] [PMID]

[22] Hosseinian A, Pakravan N, Rafiei A, Feyzbakhsh SM. Aluminum phosphide poisoning known as rice tablet: A common toxicity in North Iran. Indian J Med Sci. 2011; 65(4):143-50. [DOI:10.4103/0019-5359.104777] [PMID]
[23] Kalra G, Anand IS, Jit I, Bushnurmath B, Wahi PL. Aluminium phosphide poisoning: Haemodynamic observations. Indian Heart J. 1991; 43(3):175-8. [PMID] 